\title{
Kevin Hannam and Dan Knox (2010). Understanding Tourism: A Critical Introduction. SAGE Publications Ltd. 220 pp. ISBN 978-1-4129-2277-7
}

\author{
Reviewed by Miroslava Dimitrova
}

Received: 22/09/2010

Department of Tourism, International University College, 3 Bulgaria str., 9300 Dobrich, Bulgaria; tel: +359 58655 630; e-mail: miroslava.dimitrova@vumk.eu

(c) 2010 International University College. All rights reserved

Citation: Kevin Hannam and Dan Knox (2010). Understanding Tourism: A Critical Introduction. SAGE Publications Ltd. 220 pp. ISBN 978-1-4129-2277-7. Reviewed by Miroslava Dimitrova. European Journal of Tourism Research 3(2), pp.138-140

"Understanding Tourism" is an insightful and original approach to different aspects of tourism. It is not about clarifying what tourism is (as the title may mistakenly imply), but rather about what tourism is not by breaking some firmly rooted paradigms such as the "demand - supply" binary approach and a number of generally accepted concepts. The authors are more interested in posing questions than giving answers and their work prove to be a real inspiration for readers who are digging in the depths in search of ingenious criticism on some contemporary issues.

The book is divided into eleven chapters. Chapter One named "Introduction" presents authors' philosophy and reasoning for the book and provides a compendium on the major topics discussed later on.

Chapter Two is dedicated to issues on "Regulating tourism". The focus here is not on the governmental and professional tourism organizations, but rather on physical regulation, control and surveillance of tourists and their impact on social and natural environment.

Chapter Three entitled "Commodifying tourism" examines tourists' experiences as goods for sale at a given price. The authors assert that the exchange value for exotic culture and sensuous experience drive the contemporary tourist industry. Commodification is closely linked to commercialisation, bringing both beneficial and detrimental consequences. Trading national heritage and creation of imaginary worlds tailored for tourist consumption inevitably lead to loss of authenticity and value.

"Embodying tourism" is the subject of Chapter Four which presents an ingenuous and to some extent cynic research on physical body and its impact on tourism. This could range from bodybuilding, sports, spa \& wellness and even traditional sea-sun-sand tourism where human body is a real spectacle, zone of transformation, way of expressing and means of communication, to sex tourism where the body is blatantly commodified. This chapter 
deals with interesting issues such as nude beaching, bikini fashion, tanning etc. "Embodying tourism" acknowledges the five senses (sight, sound, touch, taste and smell) and their influence on marketing and consumption of tourism product. Authors conclude that body is both material and social, enablement and constraint and sensations need to be accounted for.

"Performing tourism" is discussed in Chapter Five, describing tourist attractions and destination as some kind of theatre where tourists see only the front-stage, while the life of the community or organization takes place in a corresponding back-stage. Most of the things tourists see or experience are far from being authentic, but are rather staged, prepared in advance either by the tourist organization or by various media that could impact tourist's perception.

Chapter Six deals with "Tourism and the everyday". According to the authors the central question is where everyday practice ends and holiday begins. The boundary between banality and leisure becomes more and more blurred, considering the progress in transport and communications. A person travelling with his/her laptop, staying in touch with the office is still performing part of his/her everyday duties even on holiday. The authors conclude that only some aspects of mundane life could be suspended by flying to different country: the identity, personality of individuals and even the daily routine will remain largely unaltered (using the same brands, eating the same food and watching the same TV programmes).

On the other hand Chapter Seven, "Tourism and the other", analyzes tourism from the perspective of exotism and change. Though tourists continue to exercise their habitual chores even while on holiday, a major motivator for undertaking a travel remains the desire to escape from the banality of everyday in search for new, adventurous and exotic environment. The chapter treats different aspects of "otherness" including language differences, orientalism versus western society, sex and gender discrimi- nation, crime, politics, religion and other cultural issues. The concept of exotic stimulates moves towards new destinations thus pulling more and more places into global tourism market.

"Tourism and the environment", as the title of Chapter Eight implies, deals with ecology and sustainable tourism development issues. The relationship between tourism and protected areas is discussed. Basic "sustainable" concepts are presented. An interesting criticism on the perception of wildlife and its level of protection is made: the authors state that some animals, which are generally perceived as "cute", due to personification in the film industry, books etc, receive more attention, while others "less attractive" species are in a disadvantageous position.

Chapter Nine, "Tourism and the past", discusses heritage tourism. It gives interesting evidences of destinations that point out certain aspects of their history while diligently hiding another not so "politically correct" periods of their past. The authors sustain the idea that history and heritage are mainly matter of interpretation with little trace of objectivism. While every country, city or even small village tries to identify a number of historic trails in order to attract visitors, heritage tourism is about telling stories and associating these stories to sites, landscapes, artifacts and people. It is not so much about presenting people the truth but confronting them with something they believe to be the truth in an engaging, stimulating and enjoyable manner.

Chapter Ten, "Tourism mobilities" acknowledges transportation and movement as vital and integral parts of tourism. The chapter discusses mobility in several aspects: human mobility (movement of tourists), mobility of goods and materials (special attention is given to food and beverages), mobile communications, advances in transportation, nodes of mobility such as airports, motorways etc and some special cases of mobility such as of viruses and infections, which could have serious impact on tourism as proved the H1N1 influenza case. 
The last Chapter Eleven gives the reader an insight about ways of "Researching tourism". Different approaches have been overviewed, such as epistemology and ontology, quantitative and qualitative research methods, interviews, participant observation and focused group researches. The chapter provides an important consideration on clarifying, planning, designing and undertaking a critical tourism research project.

Most of the statements throughout the book are backed up with interesting real life cases, thus making a successful symbiosis between theory and practice. At the end of each chapter an exercise is elaborated, presenting an opportunity for further implementation of discussed issues. The case studies and suggested questions could be easily adopted for class-room discussion, home-work preparation or self-study.

Last, but not least, the book is admirable for the interesting, vivid and shrewd style of writing which makes it really enjoyable for reading. Fun and humour are deliberately and successfully interwoven into the elevated academic analysis, thus making "Understanding Tourism, A Critical Introduction" equally valuable for professionals, academics, students and anyone else who is passionate about tourism. 